\title{
Microbes in the air - when to count! (The role of air sampling in hospitals)
}

The importance of air in the transmission of infection has always interested microbiologists, as the terms "miasma" and "malaria" indicate. Many viral, bacterial and fungal infections are spread by the airborne route and infection control procedures acknowledge this, as in the isolation of a patient with open (smear positive) tuberculosis in a single room. However, it is difficult to quantify the risk from airborne pathogens in specific infections and there are no widely accepted standards for the quality of air inhaled by hospitalised patients, although there is agreement about the need to reduce the number of bacteria in operating theatres to prevent post-operative infection. ${ }^{1}$ Interest in the environment, and its relationship with the source and transmission of infection, has increased due to the greater number of vulnerable patients in hospitals where they are exposed to food, water and air, all of which may be contaminated with potential pathogens. Severely neutropenic patients-bone-marrow, liver, kidney and heart transplant recipients, and patients on cytotoxic chemotherapy-are at particular risk. Nonetheless, there is little information on what constitutes an acceptable standard for the quality of air or when monitoring is indicated.

Wound infection caused by Staphylococcus aureus acquired in the operating theatre may be prevented, in part, by improving the bacteriological quality of air during surgery. Total numbers of bacteria in an empty operating theatre should be $<35 \mathrm{cfu} / \mathrm{m}^{3}$ with less than one colony of Clostridium perfringens or $S$. aureus. ${ }^{2}$ During an operation, total air counts should be $<180 \mathrm{cfu} / \mathrm{m}^{3}$ averaged over a 5 -min period. ${ }^{2}$ These standards have never been validated scientifically, but represent a consensus view from investigations of outbreaks of post-operative wound infections, various studies carried out under experimental conditions, and the results obtained during the commissioning of operating theatres. They serve as useful guidelines, but it would be mistaken to concentrate too much on absolute number of individual organisms. A total count of $<35 \mathrm{cfu} / \mathrm{m}^{3}$ is probably a more practical standard than individual counts of either $S$. aureus or C. perfringens. ${ }^{3}$ Bacterial air counts should be measured during the commissioning of theatres but only after all construction and engineering work has been completed. Failure to reach these bacteriological standards is usually due to correctable faults such as nesting pigeons ! ${ }^{4}$ After commissioning, there is little need for routine monitoring even in response to an apparent increase in post-operative wound infection. Air counts vary depending on the number of people in theatre, theatre design and the type of clothing worn by surgical and nursing staff. A search for engineering faults or the identification of any change in surgical practice or a breakdown in routine infection control measures are much more productive avenues of investigation in explaining an unexpected increase in wound infection rates. Risk factors for post-operative infection include surgery in the very elderly, serious underlying disease, prolonged surgery or hospital stay, and steroid or cytotoxic therapy, all of which should be considered before rushing to sample the air. The case for routine sampling in orthopaedic theatres with ultraclean air is somewhat more convincing as post-operative infection may not be manifest for some years afterwards, during which time defects may remain uncorrected. Such systems recirculate operating room air, rather than using fresh air as in conventional theatres, and monitoring orthopaedic theatres by physical means is more difficult. $^{5}$

Although hospital-acquired respiratory infection via the airborne route may occur, there are few instances in which measurement of air counts is considered useful in determining a source or as an infection control measure. Respiratory or invasive aspergillus infection acquired from an exogenous source in hospitals by immunocompromised patients is an exception to this. The risk of contracting pulmonary aspergillosis is related to the degree and duration of neutropenia in such patients. High efficiency particulate air (HEPA) filters have been advocated as a preventative measure, being less expensive than laminar air flows units. ${ }^{6}$ In practice, many patients are isolated in single rooms without either facility and the risk is probably small except during periods of building construction or if neutropenia is prolonged and severe with a neutrophil count below $0.5 \times 10^{9} / \mathrm{L}$. Counts of Aspergillus spp. measured inside and outside hospital buildings increase during construction work especially when there is major excavation of soil or demolition. ${ }^{7}$ Where a room with HEPA filters is not available, measures such as the relocation of patients, damp dusting and the erection of barriers should be instituted. Air sampling is indicated if such measures cannot be implemented. However, there are no accepted standards and $A$. fumigatus spores in concentrations of c. $1 \mathrm{cfu} / \mathrm{m}^{3}$ are found in normal air. Occasional intermittent low counts may be acceptable but persistence 
of Aspergillus spp. or increasing counts should be a cause for concern. Maintenance of a high index of clinical suspicion and the institution of treatment early in suspected cases, often before diagnosis is confirmed, is indicated in such instances.

Apart from in severely immunosuppressed patients, hospital-acquired aspergillus infection is relatively uncommon but clusters of cases have been described in Intensive Therapy Units (ITUs).$^{8,9}$ Air sampling during or after outbreaks is often unhelpful but identification of other factors such as recent hospital construction and the presence of false ceilings in the ITU may be important. ${ }^{9}$ Regular bacterial and fungal counts of air may be indicated if major construction is taking place nearby and if the unit is likely to admit neutropenic patients, those on corticosteroids or others at special risk.

When there are clear indications for air sampling, an accurate method should be used taking into account the volume of air to be sampled and the likely counts

\section{References}

1. Ayliffe GAJ. Role of the environment of the operating suite in surgical wound infection. Rev Infect Dis 1991; 13 Suppl 10: S800-S804

2. Report. Ventilation in operation suites. The report of a joint working party. Medical Research Council and Department of Health and Social Security. 1972.

3. Arrowsmith LWM. Air sampling in operating theatres. $J$ Hosp Infect 1985; 6: 352-353.

4. Holton J, Ridgeway GL, Reynoldson AJ. A microbiologist's view of commissioning operating theatres. $J$ Hosp Infect $1990 ; 16: 29-34$.

5. Whyte W, Lidwell OM, Lowbury EJL, Blowers R. Suggested expected. Agar settle plates, although inexpensive and convenient, are unsuitable as this method is not quantitative and selectively collects larger air particles. The RCS centrifugal air sampler (Biotest Folex, Birmingham) is easy to use but the sampling rate is uncertain and it is inefficient when used to detect low numbers of aspergillus. Slit samplers (Casella Ltd, Bedford) and SAS samplers (Cherwall Labs, Bicester) are simple to operate and acceptable for most investigations in which bacterial or fungal counts are required. Finally, whenever air sampling is undertaken outside a research setting, it should be carried out for a specific reason by an acceptable method and with a recognisable end-point. It is important that the results are analysed carefully and rational conclusions derived before any action is initiated.

HILARY HUMPHREYS

Department of Microbiology, University Hospital, Queen's Medical Centre, Nottingham NG7 2UH bacteriological standards for air in ultraclean operating rooms. J Hosp Infect 1983; 4: 133-139.

6. Meunier F. Prevention of mycoses in immunocompromised patients. Rev Infect Dis 1987; 9: 408-416.

7. Walsh TJ, Dixon DM. Nosocomial aspergillosis : environmental microbiology, hospital epidemiology, diagnosis and treatment. Eur J Epidemiol 1989; 5: 131-142.

8. Harvey IM, Leadbetter S, Peters TJ, Mullins J, Philphot CM, Salaman JR. An outbreak of disseminated aspergillosis associated with an intensive care unit. Community Med $1988 ; 10$ : 306-313.

9. Humphreys H, Johnson EM, Warnock DW, Willatts SM, Winter RJ, Speller DCE. An outbreak of aspergillosis in a general ITU. J Hosp Infect 1991; 18: 167-177. 